\title{
Early left ventricular functional alterations in patients with obstructive sleep apnea syndrome
}

\author{
Kezban Aslan ${ }^{1}$, Ali Deniz ${ }^{2}$, Murat Çaylı ${ }^{3}$, Hacer Bozdemir ${ }^{1}$, \\ Yakup Sarica ${ }^{1}$, Gulsah Seydaoglu ${ }^{4}$ \\ ${ }^{1}$ Çukurova University, Faculty of Medicine, Department of Neurology, Adana, Turkey \\ ${ }^{2}$ Çukurova University, Faculty of Medicine, Department of Cardiology, Adana, Turkey \\ ${ }^{3}$ Numune Research Hospital, Department of Cardiology, Adana, Turkey \\ ${ }^{4}$ Çukurova University, Faculty of Medicine, Department of Biostatistics, Adana, Turkey
}

\begin{abstract}
Background: The knowledge regarding myocardial alterations in patients with obstructive sleep apnea syndrome (OSAS) in the absence of any known cardiovascular disorders including hypertension is limited. The aim of this study was to assess the early alterations of left ventricular $(L V)$ functions caused by OSAS before the development of hypertension and other cardiovascular manifestations of OSAS.
\end{abstract}

Methods: Eighty consecutive patients who underwent polysomnography (PSG) were enrolled in the study. Patients with hypertension, diabetes mellitus or any other known cardiac diseases were excluded from the study. Subjects were separated into two groups by their apnea/hypopnea index (AHI) (group 1: AHI < 15, and group 2: AHI $\geq 15$ ). Fourty-three patients with normal polysomnographic examination or mild OSAS (group 1) and 37 patients with moderate to severe OSAS (group 2) were compared. After PSG examination, LV functions were assessed by using the conventional and tissue Doppler echocardiographic methods.

Results: The mean age was similar between the groups. The ratio of male patients was higher in group 2 (male/female: 31/12 in group 1 vs. 34/3 in group 2, $p=0.04$ ). Body mass index was higher in group $2(p=0.05)$. Conventional echocardiography showed that interventricular septum thickness was $9.5 \pm 1.1 \mathrm{~mm}$ in group 1 , and $10.5 \pm 1.4 \mathrm{~mm}$ in group $2(p=0.02)$. Mean left atrial diameter was $35.6 \pm 4.1 \mathrm{~mm}$ in group 2 , and $33.8 \pm 3.1 \mathrm{~mm}$ in group $1(p=0.04)$. Ratio of early to late transmitral diastolic velocities was lower in group $2(p=0.01)$, indicating that impairment of diastolic function was more frequent in moderate to severe OSAS patients. Tissue Doppler echocardiography showed that early diastolic myocardial velocity was lower in group $2(21.1 \pm 5.6 \mathrm{~cm} / \mathrm{s}$ in group 1 vs. $18.3 \pm 5.3 \mathrm{~cm} / \mathrm{s}$ in group $2, p=0.01)$.

Conclusions: Left ventricular diastolic dysfunction, LV hypertrophy and left atrial dilatation occur in patients with OSAS even before the development of hypertension and other cardiovascular diseases. (Cardiol J 2013; 20, 5: 519-525)

Key words: diastolic dysfunction, obstructive sleep apnea

Address for correspondence: Ali Deniz, MD, Çukurova University, Faculty of Medicine, Department of Cardiology, Saricıçam, 01100 Adana, Turkey, e-mail: alideniz78@gmail.com

Received: 16.01.2013 Accepted: 05.02.2013 


\section{Introduction}

Obstructive sleep apnea syndrome (OSAS) is a respiratory disease characterized by recurrent complete or partial obstruction of upper respiratory tract with accompanying intermittent hypoxemia and reactive waking reactions during sleep. Chronic intermittent hypoxemia during respiratory events may result in cardiovascular $(\mathrm{CV})$ disorders by causing autonomic dysfunction $[1,2]$, endothelial dysfunction [3], oxidative stress, intrathoracic pressure variations $[3,4]$, metabolic dysregulation $[5,6]$ and inflammation $[3,5]$.

Previous studies have shown the relationship between OSAS and cardiac arrhythmias and conduction abnormalities [2, 7]. The Sleep Heart Health study group has shown a 2.38-fold increase in the risk of heart failure in patients with OSAS, independent from other risk factors [8].

The most convenient and reliable method to determine left ventricular (LV) functions is echocardiographic examination. Alterations of the systolic and diastolic functions of the LV may be determined earlier, and they can be quantitatively assessed with tissue Doppler echocardiography.

The purpose of this study was to assess the early alterations of LV functions before the development of hypertension and CV manifestations of OSAS by using the conventional and tissue Doppler echocardiographic methods.

\section{Methods}

Eighty patients ( 65 men and 15 women, mean age $44.1 \pm 9.4$ years) presenting to the sleep laboratory of Çukurova University Neurology Department with the complaints of excessive daytime sleepiness and snoring who completed full-night polysomnography (PSG) were enrolled in the study. Patients with hypertension, diabetes mellitus or any known heart disease were excluded from the study.

Blood samples were collected from all patients after 12-hour fast period in the day of PSG. In addition to complete blood count and biochemistry including lipid profile, homocysteine, hs-C-reactive protein (CRP), B-type natriuretic peptide (BNP), and fibrinogen levels were measured.

\section{Sleep study}

All patients were admitted to the sleep clinic with the complaints of excessive daytime sleepiness and snoring, and they were planned to undergo full-night PSG. Full-night PSG was performed using a computerized system (Kommet,
Grass telefactor) and the following parameters were recorded: electrooculogram (2 channels), electroencephalogram (4 channels), sub-mental muscle electromyogram ( 2 channels), anterior tibial muscle electromyogram for both legs ( 2 channels), electrocardiogram (1 channel), airflow (oro-nasal pressure adjusted cannula), chest and abdominal movements respiratory inductance plethysmography (2 channels), and arterial oxyhemoglobin saturation with finger-probe pulse oximetry (SaO2: 1 channel). Records were taken at $10 \mathrm{~mm} / \mathrm{s}$ sweep rate. Sleep stages were scored according to the Rechtschaffen and Kales [9] standard criteria. Apnea was defined as complete cessation of the airflow $\geq 10 \mathrm{~s}$. Hypopnea was considered as $50 \%$ decrease in any of 3 respiratory signals (airflow signal, chest or abdominal signals) or $a \geq 1 \%$ decrease in the oxygen saturation accompanied by arousal periods. Apnea/ hypopnea index (AHI) was determined via careful calculations.

\section{Echocardiographic examination}

After PSG was completed, transthoracic echocardiographic examination was performed by a cardiologist who was blind to the results of PSG. LV diameters, interventricular septum (IVS) thickness, LV posterior wall thickness, and left atrial diameter (LAD) were measured with M-Mode echocardiography. LV ejection fraction (EF) was calculated by the modified Simpson technique. Pulsed wave Doppler was used to measure early (E) and late (A) transmitral diastolic flows, $\mathrm{E} / \mathrm{A}$ ratio, and deceleration time (DT). Systolic, early, and late diastolic myocardial velocities were recorded from lateral mitral annulus by using tissue Doppler echocardiography.

Subjects were separated into two groups by their AHI (group 1: AHI $<15$, and group 2 : $\mathrm{AHI} \geq 15$ ). Patients were compared with respect to age, sex, body mass index (BMI), sleep microstructures, minimum $\mathrm{O}_{2}$ saturation, minimum heart rate, maximum heart rate, periodic leg movement frequency, echocardiographic results.

\section{Statistics}

Distribution of the data was assessed by using one-sample Kolmogorov-Smirnov test. Continuous variables with normal distribution were expressed as mean $\pm \mathrm{SD}$, variables with skew distribution are expressed as median (minimum-maximum), categorical variables are expressed as percentage. For comparison of categorical variables or percentages we used Fisher's exact and $\chi^{2}$ tests. 
Table 1. Clinical and PSG characteristics of subjects (nonparametric results are indicated with $a n^{*}$ ).

\begin{tabular}{|c|c|c|c|}
\hline & $\begin{array}{c}\text { Group } 1(\mathrm{n}=43) ; \text { mean } \pm S D \\
{[\text { median }(\min -\max )]}\end{array}$ & $\begin{array}{c}\text { Group } 2(\mathrm{n}=37) ; \text { mean } \pm S D \\
{[\text { median }(\min -\max )]}\end{array}$ & $\mathbf{P}$ \\
\hline Sex: male/female & $31 / 12$ & $34 / 3$ & 0.04 \\
\hline Age [years] & $44.1 \pm 10.9$ & $46.0 \pm 9.4$ & 0.41 \\
\hline Body mass index $\left[\mathrm{kg} / \mathrm{m}^{2}\right]$ & $28.48 \pm 4.2$ & $31.41 \pm 4.8$ & 0.05 \\
\hline Apnea/hypopnea index & $5.3 \pm 4.5$ & $49.2 \pm 24.8$ & $<0.001$ \\
\hline Min $\mathrm{O}_{2}$ sat [\%] & $87.6 \pm 6.1$ & $70.5 \pm 16.8$ & $<0.001$ \\
\hline Min heart rate $[\mathrm{bpm}]$ & $43.9 \pm 10.6$ & $47.08 \pm 8.4$ & 0.1 \\
\hline Max heart rate $[\mathrm{bpm}]$ & $121.4 \pm 12.4$ & $114.8 \pm 16.8$ & 0.07 \\
\hline $\begin{array}{l}\text { Periodic leg movement } \\
\text { [movement } / \mathrm{h} \text { ] }\end{array}$ & $\begin{array}{l}8.5 \pm 13.8 \\
{[2.2(0-66)]}\end{array}$ & $\begin{array}{l}23.1 \pm 24.2 \\
{[10.8(0-85)]}\end{array}$ & $<0.001 *$ \\
\hline Sleep latency [min] & $17.9 \pm 12.9$ & $14.6 \pm 22.2$ & 0.4 \\
\hline Sleep time [min] & $388.7 \pm 52.8$ & $386.0 \pm 48.0$ & 0.8 \\
\hline Stage $1[\%]$ & $8.8 \pm 5.2$ & $10.6 \pm 6.5$ & 0.1 \\
\hline Stage $2[\%]$ & $59.2 \pm 10.2$ & $71.2 \pm 8.8$ & $<0.001$ \\
\hline Stage $3[\%]$ & $3.7 \pm 2.2$ & $2.1 \pm 1.9$ & 0.001 \\
\hline Stage $4[\%]$ & $15.1 \pm 5.7$ & $5.8 \pm 6.0$ & $<0.001$ \\
\hline Rapid eye movement [\%] & $13.4 \pm 6.2$ & $10.1 \pm 5.5$ & 0.02 \\
\hline
\end{tabular}

Differences between numeric variables were tested with Student's $t$-test or Mann-Whitney U-test. A p value below 0.05 was considered as statistically significant.

\section{Results}

The mean age was similar between the groups $(44.1 \pm 10.9$ years in group 1 vs. $46.0 \pm 9.4$ years in group $2 ; \mathrm{p}=0.41$ ). The number of female subjects was lower in both groups, although it was lesser in group $2(\mathrm{p}=0.04)$. The mean AHI was $5.3 \pm 4.5$ in group 1 , and $49.2 \pm 24.8$ in group 2 $(\mathrm{p}<0.001)$. BMI was significantly higher in patients with higher AHI $\left(28.5 \pm 4.2 \mathrm{~kg} / \mathrm{m}^{2}\right.$ in group $1 \mathrm{vs}$. $31.4 \pm 4.8 \mathrm{~kg} / \mathrm{m}^{2}$ in group 2) $(\mathrm{p}=0.05)$ (Table 1$)$.

According to the PSG findings, minimum $\mathrm{O}_{2}$ saturation in group 2 was significantly lower compared to group 1 ( $\mathrm{p}<0.001)$. Periodic leg movement disorder score was markedly higher in group 2 $(p<0.001)$. Assessment of sleep stages revealed no differences between the groups in terms of stage I, but stage II was longer, and stage III, IV and REM sleep were shorter in group 1 (Table 1).

Transthoracic echocardiography showed significantly increased IVS thickness and LAD in group 2 compared those of group 1 ( $p=0.02$ for IVS thickness, and $p=0.04$ for LAD). Although the mean early diastolic transmitral inflow velocity (E) was similar between the groups, late

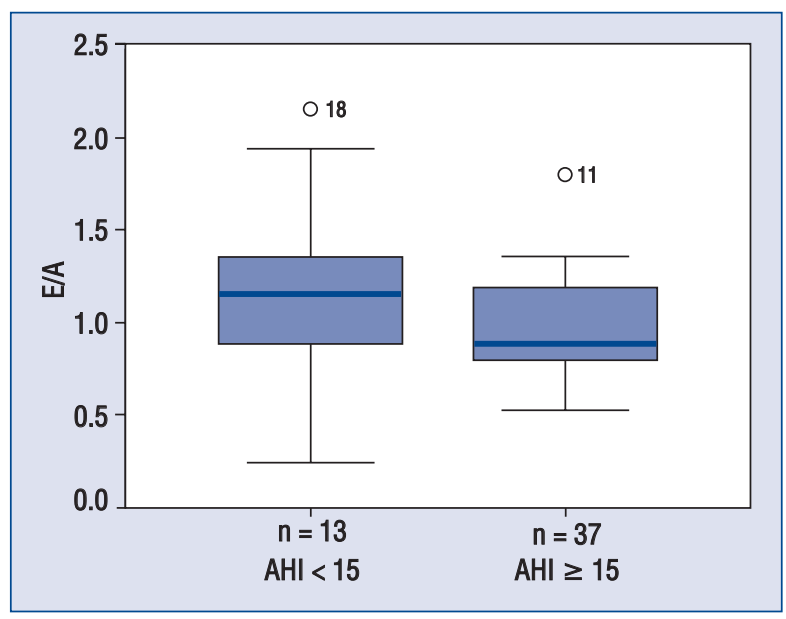

Figure 1. Boxplot graph demonstrates that $\mathrm{E} / \mathrm{A}$ ratio is lower in patients with moderate-severe obstructive sleep apnea syndrome (OSAS) compared to mild OSAS patients and normal subjects; $\mathrm{AHI}$ - apnea/hypopnea index.

diastolic transmitral inflow velocity (A) was higher in group $2(\mathrm{p}=0.01)$. $\mathrm{E} / \mathrm{A}$ ratio was significantly lower in group $2(\mathrm{p}=0.01)$ (Fig. 1). There was a weak negative correlation between $\mathrm{AHI}$ and $\mathrm{E} / \mathrm{A}$ ratio $(\mathrm{r}=-0.280, \mathrm{p}=0.01)$, and a weak positive correlation between minimum $\mathrm{O}_{2}$ saturation and $\mathrm{E} / \mathrm{A}$ ratio $(\mathrm{r}=0.288, \mathrm{p}=0.01)$ (Fig. 2). The mean $\mathrm{E}$ wave DT was not significantly 

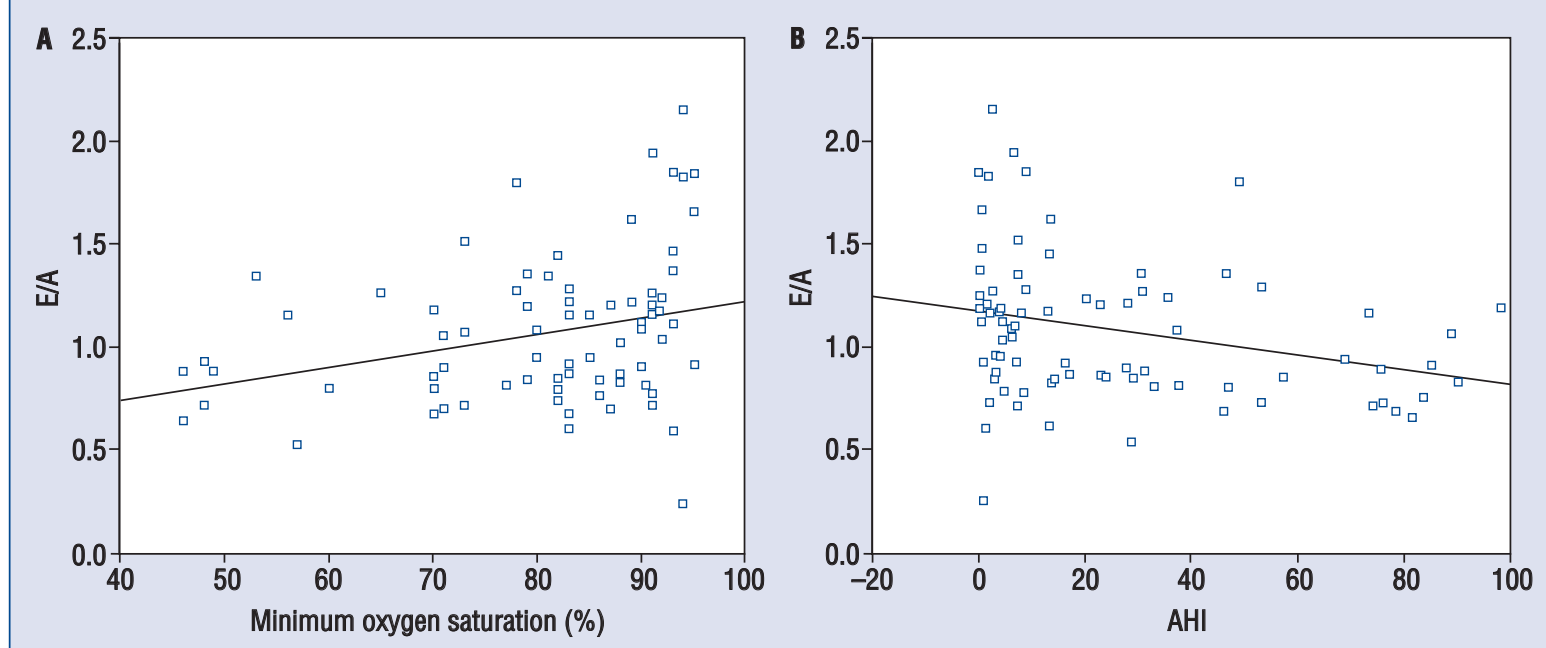

Figure 2. Scatter plo graph demonstrates that there is a weak positive correlation between nocturnal desaturation and E/A ratio (A), and weak negative correlation between apnea/hypopnea index (AHI) and E/A ratio (B).

Table 2. Echocardiography and tissue Doppler results (nonparametric results are indicated with an*).

\begin{tabular}{lccc}
\hline & $\begin{array}{c}\text { Group (n= 43); } \\
\text { mean } \pm \text { SD } \\
\text { [median (min-max)] }\end{array}$ & $\begin{array}{c}\text { Group 2 (n = 37); } \\
\text { mean } \pm \text { SD } \\
\text { [median (min-max)] }\end{array}$ & P \\
\hline Left ventricular diastolic diameter [mm] & $47.4 \pm 3.8$ & $47.5 \pm 5.9$ & 0.9 \\
Ejection fraction [\%] & $66.2 \pm 4.5$ & $66.8 \pm 5.6$ & 0.11 \\
Intraventricular septum thickness [mm] & $9.5 \pm 1.06$ & $10.5 \pm 1.4$ & $\mathbf{0 . 0 2}$ \\
Left ventricle posterior wall thickness [mm] & $9.07 \pm 0.8$ & $9.4 \pm 1.3$ & 0.1 \\
Left atrial diameter [mm] & $33.8 \pm 3.1$ & $35.6 \pm 4.05$ & $\mathbf{0 . 0 4}$ \\
Transmitral early diastolic flow (E) [cm/s] & $63.1 \pm 16.7$ & $60.4 \pm 14.6$ & 0.4 \\
Transmitral late diastolic flow (A) [cm/s] & $57.1 \pm 12.2$ & $63.8 \pm 12.1$ & $\mathbf{0 . 0 1}$ \\
E/A ratio & $1.1 \pm 0.3$ & $0.9 \pm 0.2$ & $\mathbf{0 . 0 1}$ \\
Deceleration time [ms] & $189.7 \pm 42.2$ & $201.8 \pm 59.1$ & $0.127^{*}$ \\
Systolic myocardial velocity from & {$[190(117-304)]$} & $15.5 \pm 4.2$ & 0.8 \\
lateral mitral annulus [cm/s] & $15.4 \pm 3.7$ & $18.3 \pm 5.3$ & $\mathbf{0 . 0 2}$ \\
Early diastolic myocardial velocity from & & & \\
lateral mitral annulus [cm/s] & $21.1 \pm 5.6$ & $20.2 \pm 5.5$ \\
Late diastolic myocardial velocity from & $19.7 \pm 5.7$ & & 0.6 \\
lateral mitral annulus [cm/s] & & &
\end{tabular}

different between the groups. These data demonstrated that at least some indices of LV diastolic function acquired from transmitral inflow velocities were impaired in patients with higher AHI. On the contrary, LV systolic functions evaluated by EF were similar between the groups. Tissue Doppler echocardiographic evaluation of myocardial velocities of lateral mitral annulus demonstrated that systolic myocardial velocities were also similar, while mean early diastolic myocardial velocity was lower in group $2(\mathrm{p}=0.02)$ (Table 2$)$.

Of the biochemical parameters measured during fasting conditions, blood glucose, total cholesterol, HDL cholesterol, LDL cholesterol, homocysteine, BNP, CRP and fibrinogen levels did not differ significantly between the two groups. However, triglyceride levels of group 2 were significantly higher $(\mathrm{p}=0.05)$ (Table 3$)$. 
Table 3. Comparison of biochemical values (nonparametric results are indicated with an*).

\begin{tabular}{lccc}
\hline & $\begin{array}{c}\text { Group 1 }(\mathbf{n}=\mathbf{4 3}) ; \\
\text { mean } \pm \text { SD }\end{array}$ & $\begin{array}{c}\text { Group 2 }(\mathbf{n}=\mathbf{3 7}) ; \\
\text { mean } \pm \text { SD }\end{array}$ & P \\
\hline Fasting blood glucose $[\mathrm{mg} / \mathrm{dL}]$ & $90.3 \pm 10.7$ & $95.3 \pm 11.6$ & 0.06 \\
Total cholesterol $[\mathrm{mg} / \mathrm{dL}]$ & $189.2 \pm 41.03$ & $196.6 \pm 32.1$ & 0.4 \\
HDL cholesterol $[\mathrm{mg} / \mathrm{dL}]$ & $42.9 \pm 10.1$ & $40.7 \pm 10.1$ & 0.3 \\
LDL cholesterol $[\mathrm{mg} / \mathrm{dL}]$ & $110.9 \pm 35.0$ & $113.8 \pm 28.9$ & 0.7 \\
Triglyceride $[\mathrm{mg} / \mathrm{dL}]$ & $161.8 \pm 97.3$ & $214.3 \pm 111.7$ & $\mathbf{0 . 0 5}$ \\
Homocysteine $[\mu \mathrm{mol} / \mathrm{L}]$ & $15.1 \pm 8.1$ & $16.5 \pm 12.6$ & 0.6 \\
B-type natriuretic peptide $[\mathrm{pg} / \mathrm{mL}]$ & $39.4 \pm 30.7$ & $49.7 \pm 107.2$ & 0.5 \\
C-reactive protein $[\mathrm{mg} / \mathrm{dL}]$ & $4.1 \pm 3.6$ & $4.5 \pm 2.7$ & 0.5 \\
Fibrinogen $[\mathrm{mg} / \mathrm{dL}]$ & $350.6 \pm 86.1$ & $336.5 \pm 92.1$ & 0.5 \\
\hline
\end{tabular}

\section{Discussion}

Our results demonstrated that OSAS patients with AHI greater than 15 had impaired diastolic functions, increased IVS thickness and left atrial diameter compared to patients with lower AHI in the absence of $\mathrm{CV}$ diseases (CVD) including hypertension.

Cardiovascular complications of OSAS include systemic hypertension, acute myocardial infarction, nocturnal arrhythmias, cor pulmonale and sudden nocturnal death $[2,10]$. In addition to cardiac arrhythmias, arterial hypertension secondary to autonomic instability is known as one of the worst outcomes of OSAS [2].

Conflicting results have been reported from different studies regarding the role of OSAS in CVD. Some studies have described that OSAS is not an independent risk factor in the development of CV disorders [11-13]. However, other studies have stated that the rate of mortality is significantly higher in non-treated patients with $\mathrm{AHI}$ values over 20 [14], and the incidence of CVD in non-treated patients with moderate-severe OSAS is markedly increased compared to normal individuals or treated patients [15]. This supports the point of view that OSAS is an important risk factor, particularly in case of hypertension and CVD [15-18]. Left ventricular diastolic dysfunction is a common finding in patients with hypertensive OSAS patients. OSAS is also a risk factor for the development of hypertension. Our study demonstrated that even in the absence hypertension and any other CVD, $\mathrm{LV}$ diastolic functional impairment and increase in left atrial diameters were more frequent.

It has been pointed out that hypertension, obesity, age, cholesterol levels, insulin resistance, diabetes mellitus and hypothyroidism are involved in development of CVD in patients with OSAS $[11-13,15]$. The fact that our study enrolled patients without hypertension constitutes a different perspective compared to previous studies. Among the factors that may potentially stimulate CVD, only BMI and triglyceride levels were higher to a statistically significant extent in our patient group. There were no differences between the groups in terms of age, total cholesterol, HDL and LDL cholesterol levels, and some other markers including homocysteine, BNP, CRP and fibrinogen.

Laaban et al. [17] have reported that there was no difference in hypertension prevalence between OSAS patients with and without LV dysfunction. However, Lavie et al. [19] have emphasized that OSAS affects death indirectly, most probably by being a risk factor for hypertension. Apart from these studies with differing arguments regarding hypertension - OSAS and CVD, OSAS is known to be a significant risk factor for hypertension. In a study by Marin et al. [15] a higher risk for developing CVD following OSAS diagnosis was reported for patients not diagnosed with any CVD prior to OSAS diagnosis.

Recurrent hypoxemia in OSAS increases the release of adhesion molecules and enhances inflammatory factors such as tumor necrotizing factor-alpha (TNF-alpha), interleukin-6 (IL-6), CRP and homocysteine, while reducing the synthesis of the nitric oxide (NO), known as an endothelial vasodilator factor, leading to endothelial dysfunction and development of atherosclerosis $[2,5$, $6,20,21]$. In our study, there were no significant differences between the two groups in terms of biochemical markers such as CRP, homocysteine, fibrinogen, although the difference in BMI was significant. On the other hand, triglyceride levels were significantly higher in patients with OSAS 
(Table 3). Another significant factor in OSAS apart from atherogenic biochemical-metabolic changes is the recurrent inspiratory effort [7]. Increased negative intrathoracic pressure leads to rise in the vagal tone, and decreases LV pulse volume [7, 13]. A study by Peker et al. [22] demonstrated an increased risk of developing CVD with increased desaturation index in patients with OSAS. From these perspectives, our study supports the opinion that LV dysfunctions due to increased intrathoracic pressure may occur even before nonspecific biochemical changes in OSAS patients.

Alchanatis et al. [10] determined decreased LV peak ejection rate, decreased LV peak filling rate, and delayed peak filling rate in patients with OSAS. Interestingly, the same study also reported that LV dysfunctions were not proportional with the severity of OSAS. This finding was most probably due to the low number of patients. Our results were consistent with those reported by Hedner et al. [18]. Although LV systolic function was normal in the moderate-severe OSAS patient group, diastolic dysfunction was observed both with conventional and tissue Doppler methods. In addition, IVS thickness and LAD were significantly increased in moderate-severe OSAS group compared to the mild OSAS group. It is expected that LV diastolic dysfunction, LV hypertrophy and increase in the LAD are associated with the effects of hypertension on the left ventricle. Interestingly, however, these changes were observed in patients without hypertension, suggesting that direct effect of OSAS may be involved in development of these changes.

Atrial fibrillation (AF) is known to be associated with OSAS, and the connection between OSAS severity and the frequency of AF has been well established [23]. The reason for increased AF in OSAS could be explained by LV diastolic dysfunction and increased dimensions of left atrium even in the absence of hypertension, as demonstrated in our study. Baranchuk et al. [24] have demonstrated that continuous positive airway pressure treatment reverses atrial electrical remodeling in patients with severe OSAS. These data may imply the importance of early intervention in the treatment of OSAS.

\section{Limitations of the study}

The main limitation of our study was the difference of groups with respect to BMI. It would be expected that obesity is more frequent in patients with higher AHI. Therefore, it seems to be difficult to compose the groups from patients with similar BMI with this kind of cross sectional study design. The difference of triglyceride levels were thought to be due to the difference of BMI. Another limitation was the choice of 15 arbitrarily as the cut-off for AHI to separate the groups. The reason for this cut-off value was the idea that mild OSAS would not have deleterious effects on heart independent of hypertension.

\section{Conclusions}

In conclusion, LV diastolic dysfunction, LV hypertrophy and left atrial dilatation occur in patients with OSAS even in the absence of hypertension. Left ventricular systolic function, however, is not affected during early period.

\section{Conflict of interest: none declared}

\section{References}

1. Cortelli P, Lombardi C. Sleep and autonomic nervous system dysfunction. In: Guilleminault C ed. Clinical neurophysiology of sleep disorders. Handbook of Clinical Neurophysiology. Elseiver 2005: 343-353.

2. Roche F, Xuong AN, Court-Fortune I et al. Relationship among the severity of sleep apnea syndrome, cardiac arrhythmias, and autonomic imbalance. Pacing Clin Electrophysiol, 2003; 26: 669-677.

3. Dursunoglu N, Dursunoglu D. Obstructive sleep apnea syndrome, endothelial dysfunction and coronary atherosclerosis. Tuberk Toraks, 2005; 53: 299-306.

4. Kraiczi H, Caidahl K, Samuelsson A, Peker Y, Hedner J. Impairment of vascular endothelial function and left ventricular filling: Association with the severity of apnea-induced hypoxemia during sleep. Chest 2001;119(4):1085-1091.

5. Ryan S, Nolan GM, Hannigan E, Cunningham S, Taylor C, McNicholas WT. Cardiovascular risk markers in obstructive sleep apnoea syndrome and correlation with obesity. Thorax, 2007; 62: 509-514.

6. Kokturk O, Ciftci TU, Mollarecep E, Ciftci B. Elevated C-reactive protein levels and increased cardiovascular risk in patients with obstructive sleep apnea syndrome. Int Heart J, 2005; 46: 801-809.

7. Miller WP. Cardiac arrhythmias and conduction disturbances in the sleep apnea syndrome. Prevalence and significance. Am J Med, 1982; 73: 317-321.

8. Shahar E, Whitney CW, Redline S et al. Sleep disordered breathing and cardiovascular diseases: cross-sectional results of the Sleep Heart Health Study. Am J Respir Crit Care Med, 2001; 163: 19-25.

9. Rechtschaffen A, Kales A. A manual of standardized terminology, techniques, and scoring system for sleep stages in human subjects. U.S. Government Printing Office, U.S. Public Health Service, Washington, DC 1968.

10. Alchanatis M, Tourkohoriti G, Kosmas EN, et al. Evidence for left ventricular dysfunction in patients with obstructive sleep apnoea syndrome. Eur Respir J, 2002;20(5):1239-1245.

11. Kiely JL, McNicholas WT. Cardiovascular risk factors in patients with obstructive sleep apnoea syndrome. Eur Respir J, 2000; 16: 128-133.

12. Dursunoglu N, Dursunoglu D, Ozkurt S, Kiter G, Evyapan F. Gender differences in global cardiovascular risk factors of obstructive sleep apnea patients. Tuberk Toraks, 2006; 54: 305-314. 
13. Dursunoglu D, Dursunoglu N, Evrengül H et al. Impact of obstructive sleep apnoea on left ventricular mass and global function. Eur Respir J, 2005; 26: 283-288.

14. Peter JH, Koehler U, Grote L, Podszus T. Manifestations and consequences of obstructive sleep apnoea. Eur Respir J, 1995; 8: 1572-1583.

15. Marin JM, Carrizo SJ, Vicente E, Agusti AG. Long-term cardiovascular outcomes in men with obstructive sleep apnoea-hypopnoea with or without treatment with continuous positive airway pressure: An observational study. Lancet, 2005; 365: 1046-1053.

16. Kraiczi H, Peker Y, Caidahl K, Samuelsson A, Hedner J. Blood pressure, cardiac structure and severity of obstructive sleep apnea in a sleep clinic population. J Hypertens, 2001; 19: 2071-2078.

17. Laaban JP, Pascal-Sebaoun S, Bloch E, Orvoën-Frija E, Oppert JM, Huchon G. Left ventricular systolic dysfunction in patients with obstructive sleep apnea syndrome. Chest, 2002; 122: 1133-1138.

18. Hedner J, Ejnell H, Caidahl K. Left ventricular hypertrophy independent of hypertension in patients with obstructive sleep apnoea. J Hypertens, 1990; 8: 941-946.
19. Lavie P, Herer P, Peled R et al. Mortality in sleep apnea patients: A multivariate analysis of risk factors. Sleep, 1995; 18: 149-157.

20. Oliveira GH. Novel serologic markers of cardiovascular risk. Curr Atheroscler Rep, 2005; 7: 148-154.

21. Kokturk O, Ciftci TU, Mollarecep E, Ciftci B. Serum homocysteine levels and cardiovascular morbidity in obstructive sleep apnea syndrome. Respir Med, 2006; 100: 536-541.

22. Peker Y, Hedner J, Kraiczi H, Löth S. Respiratory disturbance index: An independent predictor of mortality in coronary artery disease. Am J Respir Crit Care Med, 2000; 162: 81-86.

23. Todd K, McIntyre WF, Baranchuk A. Obstructive sleep apnea and atrial fibrillation: A review of the literature. Nature Science Sleep, 2010; 2: 39-45.

24. Baranchuk A, Pang H, Seaborn GE et al. Reverse atrial electrical remodelling induced by continuous positive airway pressure in patients with severe obstructive sleep apnoea. J Inerv Card Electrophysiol, DOI 10.1007/s10840-012-9749-3. 